\title{
Interactions of perturbations in intrauterine growth and growth during childhood on the risk of adult-onset disease
}

\author{
Chittaranjan Yajnik \\ Diabetes Unit, King Edward Memorial Hospital and Research Centre, Pune 411011, India
}

\begin{abstract}
The 'fetal origins' hypothesis (Barker, 1995) would predict that the rising epidemic of diabetes and CHD in India would be due to poor intrauterine growth of the Indian babies. While this explanation may be valid to an extent, the higher prevalence of these disorders in urban compared with rural India (where birth weights are lower) would suggest a significant role for postnatal factors. In a cohort of 477 children born in the King Edward Memorial Hospital, Pune, we found that at 8 years of age current obesity strongly predicted insulin resistance. When this effect was allowed for, low birth weight was significantly associated with insulin-resistance variables and other cardiovascular risk factors. Children who were born small but had grown heavy (or tall) were the most insulin resistant and had the highest levels of cardiovascular risk factors. Accelerated growth in relation to mid parental height was similarly predictive. Poor intrauterine growth also predicted higher central adiposity at 8 years of age. We have also studied maternal nutrition and fetal growth in six villages near Pune. A newborn Indian baby is small (2650 g, SD score (SDS) 1.6 compared with an average white Caucasian baby born in the UK) and 'thin' (ponderal index $2.45 \mathrm{~kg} / \mathrm{m}^{3}$, SDS $-1 \cdot 2$ ), but has preserved its subcutaneous fat (subscapular skinfold thickness SDS -0.6). The thinness of the Indian babies is due to poor muscle and small abdominal viscera. We have proposed this composition as the 'thrifty phenotype' (Hales \& Barker, 1992) of Indian babies. Maternal size and intake of certain food groups during pregnancy were important determinants of the baby's phenotype. Thus, the small Indian babies are programmed to deposit fat from their intrauterine life. Exaggeration of this tendency in later life is associated with insulinresistance syndrome. Control of the insulin-resistance epidemic in India might depend on improved intrauterine development and prevention of childhood obesity.
\end{abstract}

Insulin resistance: Type 2 diabetes: Coronary heart disease:

Intrauterine growth retardation: Childhood obesity: Indian babies

\section{Changing scene of degenerative diseases}

The traditional view of the nutritional risk for chronic degenerative diseases (diabetes, hypertension and CHD) consists of the relationships between increased prevalence of these disorders and obesity, excess dietary intake of energy, fats and salt, and reduced physical activity. Not long ago these degenerative diseases were considered diseases of affluence and overnutrition. Over the last few decades some developed countries have shown a decline in the prevalence of $\mathrm{CHD}$; in some of these countries the prevalence has shown a trend which is the reverse of the socio-economic gradient (i.e. affecting the poor more than the rich). At the same time, many of the developing countries (previously thought to be protected) are facing a rapidly-rising epidemic of diabetes and CHD.

\section{Genes and environment}

The occurrence of diabetes and other related disorders has been linked traditionally to a 'thrifty genotype' which, it is proposed, enhanced survival under subsistence conditions existing in the past, but becomes detrimental in the modern context of plentiful food and reduced physical activity (Neel, 1962). The most obvious phenotypic expression of the thrifty genotype is obesity. Although teleologically a useful concept, no specific gene markers have yet been described. A recently-proposed alternative explanation is the 'fetal origins' (Barker, 1995) or the 'thrifty phenotype' hypothesis (Hales \& Barker, 1992). Barker et al. (1989) observed a strong geographical association between mortality from CHD in adults and infant mortality around the time the subjects were born. Thus, CHD mortality was 
high in the relatively poor areas in Britain where infant mortality was high. They reasoned that high infant mortality reflected intrauterine malnutrition in these communities. In a series of brilliant epidemiological studies Barker (1998) demonstrated, in different regions of the UK, a strong association between poor intrauterine growth (measured as low birth weight, short length, thinness, smaller head circumference etc.) and adult cardiovascular disease and type 2 diabetes. Soon it became clear that the strongest relationship was between poor intrauterine growth and the prevalence of the so-called 'insulin-resistance syndrome' (IRS; also called 'syndrome X'; glucose intolerance, highcirculating triacylglycerol and low HDL-cholesterol concentrations, hypertension and CHD). Initially received with scepticism, the relationship between poor intrauterine growth and adult IRS has been demonstrated in different populations of the world (Barker, 1998). 'Barkerology' is now an accepted phenomenon.

\section{Fetal programming}

Although the concept of 'fetal origins' is now well established, the mechanisms involved are not clear. It has been suggested that a growing fetus faced with adverse conditions responds with endocrine, metabolic and vascular or other structural adaptations (Barker et al. 1993a; Barker, 1995, 1998). The commonest adversity for the fetus may be 'malnutrition'. The first priority for a developing fetus is survival, and during the 'lean' periods survival is achieved by a reduced rate of growth (intrauterine growth retardation). The time during intrauterine life when this reduced rate of growth occurs determines the systems affected. The 'fetal origins' hypothesis suggests that these adjustments are 'imprinted', affecting the response of the system in future life ('programming'). Insulin resistance seems to be one such survival mechanism in response to fetal malnutrition. Poor maternal nutrition could be the most common cause of fetal malnutrition, but there is currently no conclusive evidence. Maternal 'nutrition' could thus determine the future risk of type 2 diabetes and CHD in the offspring, which could have profound implications for prevention of these disorders in future generations.

\section{Environment: early life, later life or both?}

The relationship between poor intrauterine growth (mostly represented by low birth weight) and IRS and cardiovascular disease was obvious only when adjustment was made in the statistical analysis for the effect of current (adult) obesity (Hales et al. 1991). For some time, attention was focused only on the intrauterine environment, which was the new exciting discovery. However, the worst sufferers of IRS were always those who were born small but had grown big in later life.

\section{The Third World scene}

The majority of research into 'fetal origins' has been done in the UK and other developed countries where birth records of individuals born in the early part of this century were available. The largest burden of intrauterine malnutrition is, of course, in the developing world. In India mothers suffer from chronic malnutrition, and one-third of the babies are born with a low birth weight $(<2.5 \mathrm{~kg})$, predominantly due to an asymmetric growth retardation (Gopalan, 1994). There has been an explosion of diabetes and CHD during the last few decades, especially in the urban areas (Gupta \& Gupta, 1996; Ramachandran et al. 1997). There is, thus, a priori reason to believe that 'fetal origins' could contribute to this epidemic. However, there is an obvious paradox in the Indian scenario. Maternal malnutrition is more widespread and birth weights are lower in rural India (approximately $2700 \mathrm{~g}$ ) than those in the cities (approximately $2900 \mathrm{~g}$ ). These factors would predict a higher prevalence of diabetes and CHD in rural India if 'fetal origins' was the only explanation. The situation is exactly the opposite; diabetes and CHD are at least four times more common in the cities than in the villages. The explanation for this 'paradox' is found in the adult body size. The mean BMI of adult rural Indians is $19.0 \mathrm{~kg} / \mathrm{m}^{2}$, while that of urban adults is $23 \mathrm{~kg} / \mathrm{m}^{2}$. Thus, the urban adults outgrow their rural counterparts by $130 \%$, while they were only $109 \%$ larger at birth. Factors related to postnatal growth clearly influence the cardiovascular risk, probably with the background of intrauterine programming.

\section{Studies in Indian children \\ Risk of being small}

In collaboration with Professor David Barker and Dr Caroline Fall we investigated the relationship between birth weight and glucose and insulin metabolism in 4-year-old children born in the King Edward Memorial Hospital, Pune (Yajnik et al. 1995). Birth weights were available in the labour room register. We traced over 200 children whose birth weight was $>2.0 \mathrm{~kg}$ at term and who had not required any special postnatal care. A standard oral glucose tolerance test $(1.75 \mathrm{~g}$ anhydrous glucose $/ \mathrm{kg}$ load) was performed, and circulating concentrations of glucose, insulin, insulin-like growth factor-1, lipids (total and HDL-cholesterol and triacylglycerols) and blood pressure were measured. Growth was assessed by detailed anthropometry (Yajnik et al. 1995).

Plasma glucose and insulin concentrations were strongly related to current weight and body fat measures (skinfold thicknesses). When this strong influence of current body size was adjusted for in the statistical analysis, plasma glucose and insulin concentrations $30 \mathrm{~min}$ after the glucose load were inversely related to birth weight (Fig. 1 ( $a$ and b)). There was an interaction between birth weight and subsequent growth; children who were born small and had grown big at 4 years of age had the highest plasma glucose and insulin concentrations $30 \mathrm{~min}$ after oral glucose load. A combination of higher glucose concentrations with higher insulin concentrations are indicative of insensitivity of the peripheral tissues to the metabolic actions of insulin, particularly in the muscle and the adipose tissue. We also noticed an inverse relationship between head circumference at 4 years of age and $30 \mathrm{~min}$ plasma glucose and insulin concentrations. A substantial part of the head circumference (two-thirds of the adult size) is attained at birth, and thus the 

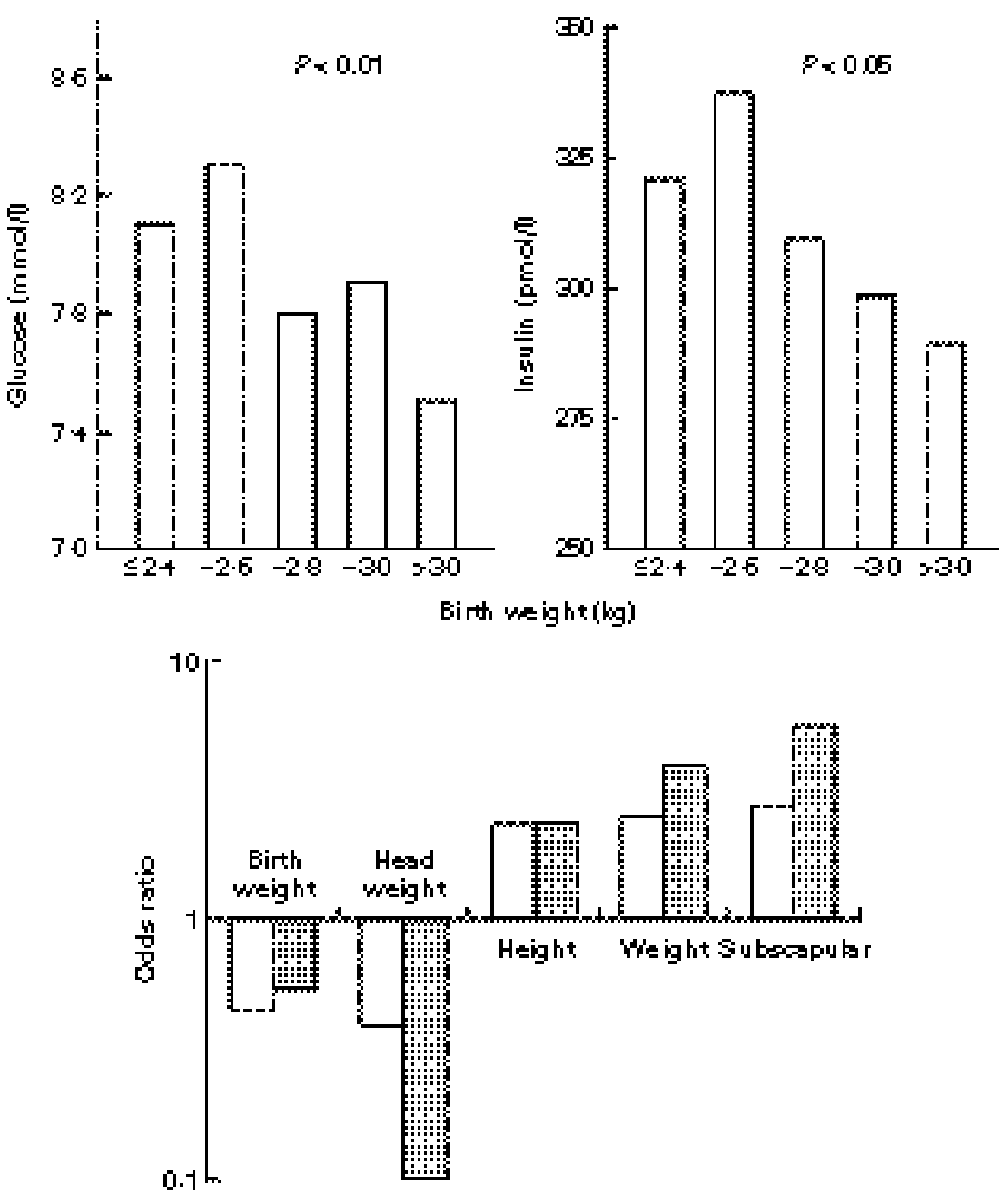

Fig. 1. (a) Plasma glucose and insulin concentrations $30 \mathrm{~min}$ after an oral glucose load in 4-year old Indian children by categories of birth weight. The significance of the trend was corrected for age, sex and current weight. (Based on Yajnik et al. 1995). (b) Relative risk of belonging to the highest quartile of plasma glucose and insulin concentrations $30 \mathrm{~min}$ after an oral glucose load between extreme quartiles of birth weight and anthropometric measurements at 4 years of age. $(\square)$, Glucose; $\square$ ), insulin; head, subscapular, subscapular skinfold thickness.

4-year measurement is a surrogate measure, at least in part, of intrauterine growth. We thus interpreted this finding as confirming the relationship between poor intrauterine nutrition and subsequent development of insulin resistance. Birth weight was inversely related to blood pressure but not related to fasting and 120 min plasma glucose and insulin concentrations, and was not consistently related to circulating lipid concentrations.

\section{Risks of being born small and growing big}

We studied these children again at 8 years of age. Additional children were included in the study to expand the range of birth weights. A total of 477 children, and their parents (Table 1) were studied. The design of the study was similar to that used at 4 years of age (Bavdekar et al. 1999). The findings have improved our understanding of the interaction between intrauterine and postnatal growth in relation to subsequent development of IRS and the cardiovascular risk.

We (Bavdekar et al. 1999) confirmed the strong and direct relationship between current indices of 'obesity'
Table 1. Anthropometric measurements for 8-year-old Indian children and their parents, with fewer fathers participating (Values are means)

\begin{tabular}{|c|c|c|}
\hline & Girls (n 221) & Boys (n 256) \\
\hline Birth wt $(\mathrm{kg}) \dagger$ & $2 \cdot 7$ & $2 \cdot 8^{*}$ \\
\hline Wt (kg) & $21 \cdot 3$ & $22 \cdot 0$ \\
\hline Height (m) & $1 \cdot 247$ & $1 \cdot 254$ \\
\hline $\mathrm{MAC}(\mathrm{mm})$ & 163 & 162 \\
\hline Head $(\mathrm{mm}) \ddagger$ & 499 & $504^{*}$ \\
\hline Triceps (mm)†§ & $8 \cdot 1$ & $6 \cdot 7^{\star \star *}$ \\
\hline \multirow[t]{2}{*}{ Subscapular $(\mathrm{mm}) \dagger \S$} & $6 \cdot 5$ & $5 \cdot 5^{* * *}$ \\
\hline & Fathers $(n 395)$ & Mothers ( $n$ 459) \\
\hline Age (years) & 38 & 32 \\
\hline Wt $(\mathrm{kg})$ & $63 \cdot 3$ & $52 \cdot 4$ \\
\hline Height (m) & 1.660 & 1.531 \\
\hline BMI $\left(\mathrm{kg} / \mathrm{m}^{2}\right)$ & $22 \cdot 9$ & $22 \cdot 3$ \\
\hline
\end{tabular}

MAC, mid-arm circumference.

Values were significantly different from those for girls: * $P<0.05$, ${ }^{* \star *} P<0.001$. $\dagger$ Note low birth weights and lack of obesity at 8 years of age.

$\ddagger$ Head circumference.

$\S$ Triceps and subscapular skinfold thicknesses. 
(weight, BMI and calculated fat mass) and components of the IRS (plasma glucose, insulin and triacylglycerol concentrations, systolic blood pressure and the insulin-resistance variable (HOMA-R; based on the homeostasis model assessment of Matthews et al. 1985); Table 2). Obesity was also related to plasma total cholesterol concentration and to LDL-cholesterol concentration (results not shown). At 8 years of age after adjusting for current obesity indices, birth weight was inversely related to a range of cardiovascular risk factors, including many IRS variables. The highest levels of insulin resistance (Fig. 2) and other cardiovascular risk factors were found in children who were born small and had grown 'big'. Insulin resistance (HOMA-R) and plasma cholesterol concentration were related not only to indices of obesity at 8 years of age, but also to the height of the child (Table 2). Such a relationship has previously not been described in children. Intriguingly, insulin resistance in children was inversely related to mid parental height, i.e. children born to shorter parents were more insulin resistant than those born to taller parents. Both maternal and paternal

Table 2. Correlations between cardiovascular risk factors at 4 and 8 years of age and birth weight and concomitant anthropometric measures for Indian children

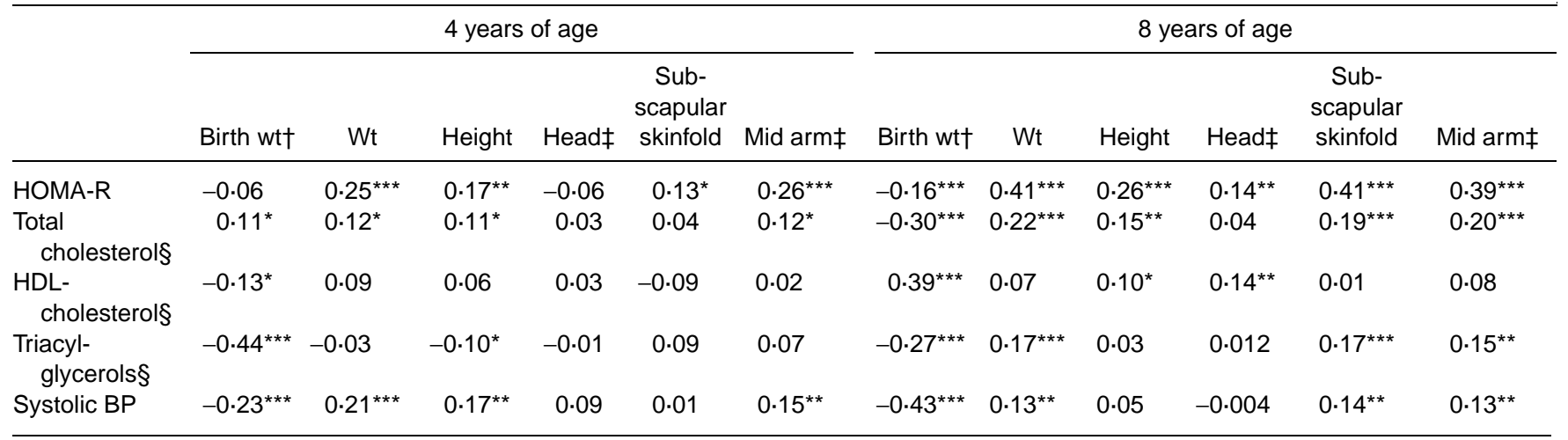

HOMA-R, calculated insulin resistance variable (based on the homeostasis model assessment of Matthews et al. 1985); BP, blood pressure.

${ }^{*} P<0.05,{ }^{* *} P<0.01,{ }^{* *} P<0.001$ (adjusted for age and sex).

$\dagger$ Correlation coefficients for birth weight were adjusted for age, sex and weight at both 4 and 8 years.

$\ddagger$ The circumference was measured.

$\S$ Plasma concentrations.
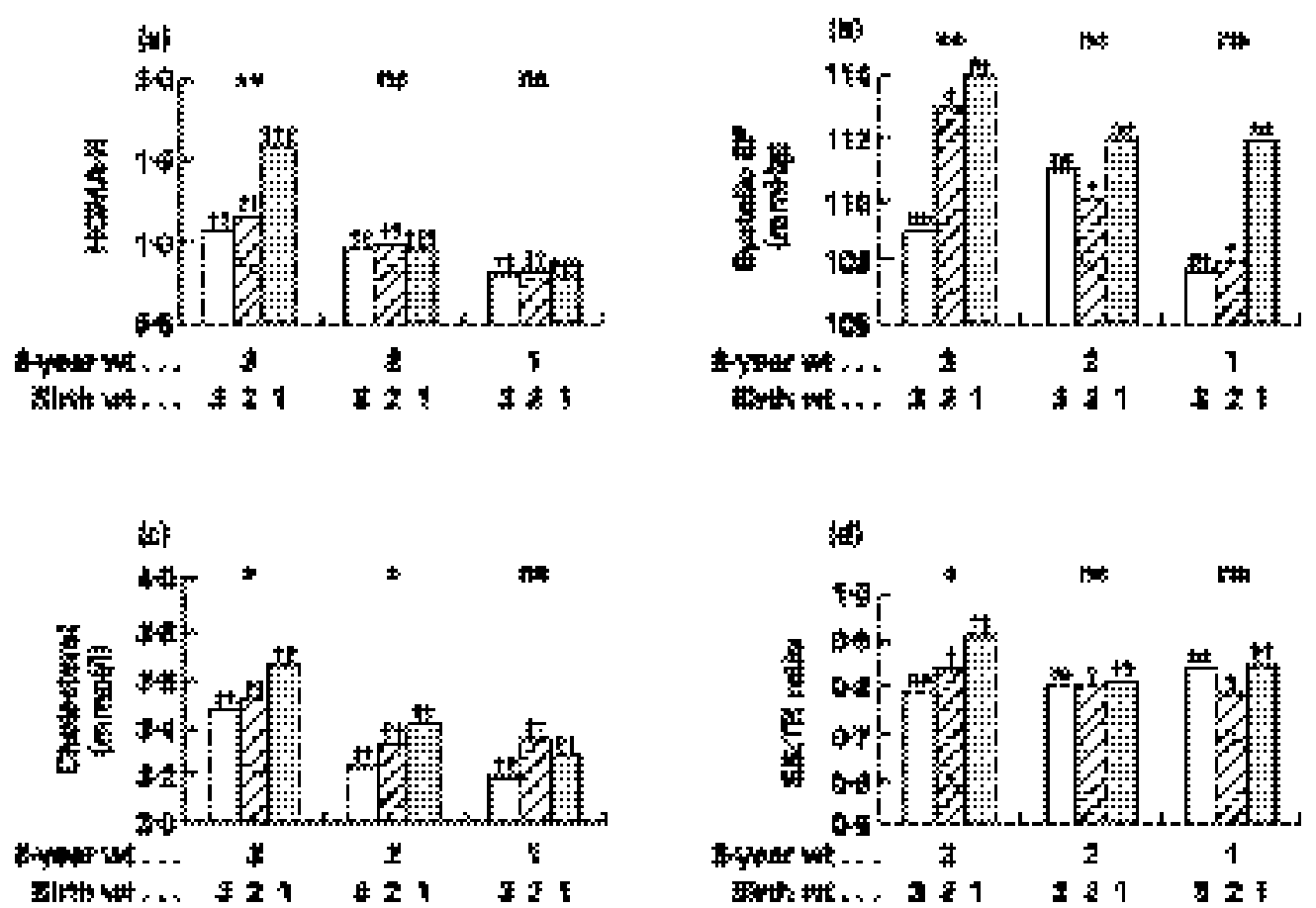

Fig. 2. (a) Mean levels of insulin-resistance variable (HOMA-R; calculated index of insulin resistance based on the homeostasis model assessment of Matthews et al. (1985)), (b) systolic blood pressure (BP), (c) serum cholesterol concentration and (d) subscapular: triceps skinfold thickness (SS:TR) at 8 years of age by tertiles (1,2 and 3) of birth weight and 8-year weight. The trends for birth weight and 8-year weight (adjusted for age and sex) were significant: 8-year weight ${ }^{*} P<0.05$, ${ }^{* \star} P<0.01$; for birth weight $\dagger P<0.05, \emptyset \dagger P<0.01$, $\dagger \dagger \dagger P<0.001$. (Based on Bavdekar et al. 1999.) 
height contributed independently to this relationship. Even more interestingly, children who had grown fatter and taller in relation to mid parental height were the most insulin resistant (Fig. 3).

We investigated the characteristics of children who possessed more than one IRS variable. Increasing expression of IRS was associated with increasing current obesity (weight and fat mass), increasing central adiposity (subscapular: triceps skinfold thickness) and increasing height but decreasing birth weight (Table 3). Thus, IRS expressed progressively more severely in low-birth-weight children who grew progressively more 'fat' or 'tall' during childhood. 'Catch-up' growth thus appears to be associated with an adverse profile of IRS and cardiovascular risk. Growth velocity for each component of growth between 4 and 8 years of age (weight, fat mass, height, head circumference and muscle (mid-arm circumference)) was even more strongly associated with insulin resistance than the individual measures at 8 years of age (Table 4 ).

We have thus noticed a very interesting interaction between intrauterine growth and postnatal growth, as well as growth velocity, in relation to the IRS in childhood. Indian children are relatively small and thin by international standards (Table 1) and, therefore, an imbalance or discordance between intrauterine and postnatal growth



seems more strongly associated with insulin resistance than poor intrauterine growth or childhood 'obesity' alone. An 'upward' movement on the trajectory of growth started in utero ('centile gain') is associated with higher insulin resistance.

Our findings support and expand on the observations made in two previous studies in children. Whincup et al. (1997) studied over 1000 children at a mean age of 10 years. They showed that childhood growth was a much stronger determinant of glucose tolerance and insulin resistance (fasting plasma insulin concentration and HOMA-R) than birth size. There was an interaction between intrauterine growth (low birth weight and ponderal index (weight/length ${ }^{3}$ )) and subsequent growth such that those children who were born small but subsequently 'caught up' were the most insulin resistant (Fig. 4). Crowther et al. (1998) reported on black children from South Africa (Table 5). Low birth weight was associated with higher 30 min glucose concentrations during an oral glucose-tolerance test at the age of 7 years. The relationships involving current obesity (BMI) were much stronger and were found with a wider range of glucose and insulin variables. Growth velocity for weight was a strong predictor of insulin resistance at 7 years of age. Authors concluded that intrauterine growth retardation coupled with increased

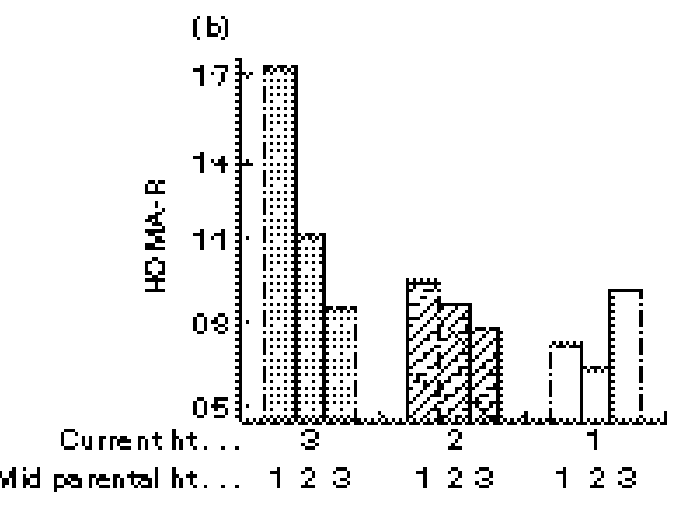

Fig. 3. Mean levels of insulin-resistance variable (HOMA-R; calculated index of insulin resistance based on the homeostasis model assessment of Matthews et al. (1985)) at 8 years of age by tertiles (1,2 and 3) of current weight (a) and current height (b) and mid parental height. Children born to short parents but heavier or taller at 8 years of age were most insulin resistant. (Based on Bavdekar et al. 1999.)

Table 3. Clustering of insulin-resistance variablest, birth weight and anthropometric measures at 8 years of age for Indian children (Values are means for the no. of subjects shown)

\begin{tabular}{|c|c|c|c|c|c|c|c|}
\hline & $n$ & $\begin{array}{l}\text { Birth wt } \\
(\mathrm{kg})\end{array}$ & $\begin{array}{l}\text { 8-year wt } \\
(\mathrm{kg})\end{array}$ & $\begin{array}{l}\text { 8-year height } \\
(\mathrm{m})\end{array}$ & $\begin{array}{l}\text { 8-year fat mass } \\
(\mathrm{kg})\end{array}$ & $\begin{array}{l}8 \text { year } \\
\text { SS:TR }\end{array}$ & $\begin{array}{l}\text { Fasting insulin } \\
(\mathrm{pmol} / \mathrm{l})\end{array}$ \\
\hline Non resistant & 364 & $2 \cdot 78$ & $20 \cdot 4$ & $1 \cdot 242$ & $3 \cdot 21$ & $0 \cdot 81$ & $20 \cdot 0$ \\
\hline HOMA-R & 83 & $2 \cdot 72$ & $23 \cdot 3$ & $1 \cdot 276$ & 4.03 & $0 \cdot 81$ & $40 \cdot 3$ \\
\hline $\mathrm{HOMA}-\mathrm{R}+\mathrm{BP}$ & 16 & 2.46 & $23 \cdot 3$ & $1 \cdot 291$ & $3 \cdot 89$ & $1 \cdot 24$ & $44 \cdot 7$ \\
\hline $\mathrm{HOMA}-\mathrm{R}+\mathrm{BP}+\mathrm{TG}$ & 11 & $2 \cdot 75$ & $27 \cdot 5$ & 1.309 & $6 \cdot 52$ & 1.04 & $63 \cdot 7$ \\
\hline $\mathrm{HOMA}-\mathrm{R}+\mathrm{BP}+\mathrm{TG}+\mathrm{HDL}$-cholesterol & 3 & $2 \cdot 36$ & $30 \cdot 7$ & $1 \cdot 296$ & $6 \cdot 85$ & 0.97 & $63 \cdot 0$ \\
\hline$P \neq$ & & $* * *$ & $* \star \star *$ & *** & $* * *$ & * & *** \\
\hline
\end{tabular}

SS : TR, subscapular : triceps skinfold thickness; BP, systolic blood pressure; TG, triacylglycerols.

${ }^{*} P<0.05,{ }^{* * *} P<0.001$.

† Insulin resistance was calculated based on the homeostasis model assessment of Matthews etal. (1985); children belonging to the highest quartile are termed resistant (HOMA-R), other children are termed non resistant. Insulin-resistant children who also belonged to the highest quartile of systolic blood pressure and plasma triacylglycerol concentration, and to the lowest quartile of plasma HDL-cholesterol concentration were progressively larger at 8 years in all body measurements, and had progressively lower birth weights (adjusted for 8-year weight).

$\ddagger$ Significance for trend adjusted for age and sex, the birth weight is also adjusted for 8-year weight. 
Table 4. Correlations between growth velocity for each component of growth and insulin resistance ${ }^{*} \dagger$

\begin{tabular}{lcc}
\hline $\begin{array}{l}\text { Growth velocity } \\
\text { component }\end{array}$ & $\begin{array}{c}\text { Correlation } \\
\text { coefficient }\end{array}$ & $P \neq$ \\
\hline $\begin{array}{l}\text { Birth - 4 years } \\
\text { Weight }\end{array}$ & 0.18 & $<0.05$ \\
4-8 years & 0.50 & $<0.001$ \\
Weight & 0.36 & $<0.01$ \\
Height & 0.24 & $<0.01$ \\
Head circumference & 0.42 & $<0.01$ \\
Subscapular skinfold thickness & 0.37 & $<0.01$ \\
Triceps skinfold thickness & 0.41 & $<0.01$ \\
Mid-arm circumference &
\end{tabular}

* Insulin resistance variable was calculated based on the homeostatis model assessment of Matthews et al. (1985).

$\dagger n 190$.

$\ddagger$ Adjusted for age and sex.

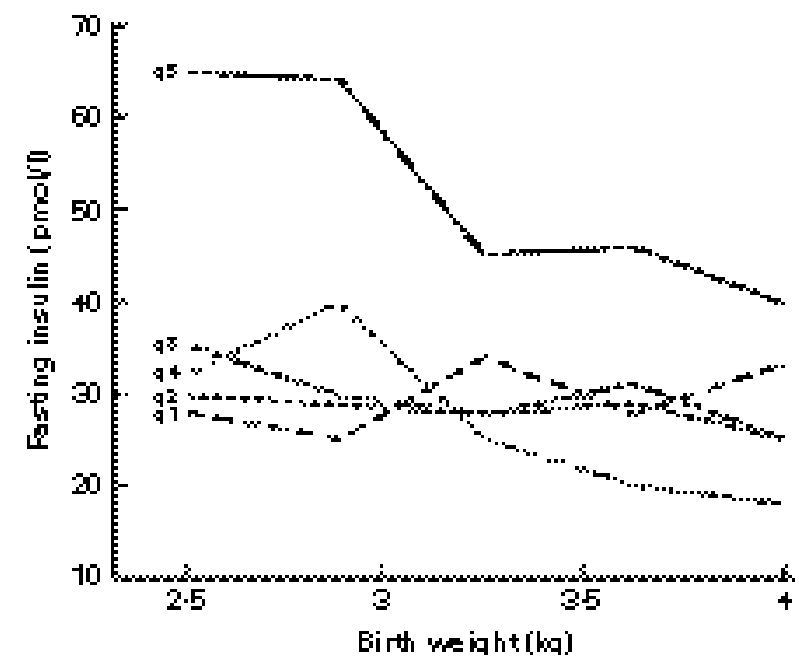

Fig. 4. Fasting plasma insulin concentrations in 591 white Caucasian 10-year-old children by categories of their birth weight and quintiles of ponderal index (weight/height ${ }^{3}$ ) at 10 years of age (q1-q5). (Based on Whincup et al. 1997.)

growth velocity during postnatal life was related to insulin resistance.

Studies in adult populations have also shown an interaction between small birth size and adult obesity (BMI) in relation to IRS outcomes (diabetes and CHD). For example, diabetes and impaired glucose tolerance were more common in individuals who had a low birth weight but were obese at 65 years of age (Hales et al. 1991). Similarly syndrome X was most prevalent in those who were born small but who had subsequently grown obese as adults (Barker et al. 1993b). A recent study in Finland was able to trace not only the birth records but also the childhood growth in a large cohort of people (Eriksson et al. 1999). Mortality from CHD was higher in those individuals who had a low birth weight and were thin at birth (low ponderal index). Cardiovascular mortality was even higher in those individuals who were born small but became obese as children. The childhood growth curve (BMI) of subjects who died of cardiovascular disease was persistently above the median for the whole population. In a study of subjects born in Mysore (India), the
Table 5. Correlations between birth weight and postnatal growth variables and circulating glucose and insulin concentrations (30 and $120 \mathrm{~min}$ after an oral glucose load) and calculated insulin-resistance variable (HOMA-R) at 7 years of age in 152 black South African children (Based on Crowther et al. 1998)

\begin{tabular}{|c|c|c|c|c|}
\hline & \multirow{2}{*}{$\frac{\text { Glucose }}{30 \mathrm{~min}}$} & \multicolumn{2}{|c|}{ Insulin } & \multirow[b]{2}{*}{ HOMA-R } \\
\hline & & $30 \mathrm{~min}$ & $120 \mathrm{~min}$ & \\
\hline Birth weight & $(-) 0.20^{*}$ & - & - & - \\
\hline Height at 1 year & $(-) 0.19$ & - & - & - \\
\hline $\begin{array}{l}\text { Subscapular† at } 5 \\
\text { years }\end{array}$ & $0.19^{*}$ & $0 \cdot 23^{* *}$ & - & - \\
\hline Triceps $†$ at 5 years & $0 \cdot 21^{*}$ & $0 \cdot 22^{*}$ & $0 \cdot 19^{*}$ & - \\
\hline Height at 7 years & $(-) 0.22^{*}$ & - & - & - \\
\hline BMI at 7 years & - & $0 \cdot 40^{\star * *}$ & $0 \cdot 27^{\star \star}$ & $0 \cdot 24^{*}$ \\
\hline $\begin{array}{l}\text { Weight velocity } \\
\text { (birth }-7 \text { years) }\end{array}$ & - & $0 \cdot 36^{\star *}$ & $0.30^{\star \star}$ & $0 \cdot 18^{*}$ \\
\hline
\end{tabular}

${ }^{*} P<0.05,{ }^{* *} P<0.01,{ }^{* * *} P<0.001$.

† Subscapular and triceps skinfold thickness.

$\ddagger$ Based on the homeostasis model assessment of Matthews et al. (1985).

highest prevalence of CHD at 45 years of age was found in individuals who had lower weight, height or head circumference at birth, but who had 'normal' weight as adults (Stein et al. 1996). Thus, poor intrauterine growth reduces the threshold of risk of adult obesity, because the 'normal' adult weight represents an 'upward' movement during postnatal growth in the small babies. In populations where low birth weight is common this factor would mean that the risk of IRS will be much higher at relatively lower adult BMI compared with the well-nourished populations. This situation is dramatically obvious in rural Indian adults. We studied adults $>40$ years of age ( $n$ 321, mean age 55 years) in the village of Pimpale Jagtap near Pune City (Shelgikar \& Yajnik, 1997). The mean BMI was $19 \mathrm{~kg} / \mathrm{m}^{2}$. The relative risk for men in the highest quartile of BMI (mean $23.5 \mathrm{~kg} / \mathrm{m}^{2}$ ) compared with those in the lowest quartile (mean $16.5 \mathrm{~kg} / \mathrm{m}^{2}$ ) was 2.04 for glucose intolerance (impaired glucose tolerance + diabetes, WHO criteria), 4.51 for hypertension (blood pressure $\geq 140 / 90 \mathrm{mmHg}$ ) and 1.54 for CHD (Rose-WHO questionnaire (Rose et al. 1982) and Minnesota coded resting electrocardiogram). Clearly, there is a need to reconsider the BMI criteria of obesity in the developing world.

\section{Intrauterine malnutrition and subsequent obesity}

Young Dutch adults born to mothers who faced famine conditions during early gestation showed an excess risk of obesity (Ravelli et al. 1976). The association between poor intrauterine growth and later obesity (BMI) has been reviewed (Strauss, 1997; Whitaker \& Dietz, 1998). It is now clear that central (predominantly visceral) fat distribution is an even more powerful risk factor for the IRS than the total body fat. In our study of 8-year-old children we noticed a significant relationship between low birth weight and high subscapular:triceps skinfold thickness, which is thought to be a better indicator of central fat deposition in children than waist:hip. Low birth weight has been shown to be associated with higher waist:hip (Law et al. 1992) and higher subscapular: triceps skinfold thickness (Valdez et al. 1994) 
in adults, and with higher subscapular:triceps skinfold thickness in children (Malina et al. 1996; Bavdekar et al. 1999) and adolescents (Barker et al. 1997). It would appear that the malnourished fetus preferentially deposits fat in the truncal region during postnatal life.

\section{Intrauterine growth of Indian babies: a thrifty phenotype}

We had a unique opportunity to study fetal growth and body composition in relation to maternal nutrition in six villages near Pune (Pune Maternal Nutrition Study; Fall et al. 1999). We studied over 800 pregnancies in mothers whose anthropometry was measured serially from before the time they became pregnant. Maternal food intake, physical activity, biochemical variables and fetal growth (ultrasound) were studied during pregnancy. Babies were measured in detail at birth. Mothers were small and thin (mean weight $42 \mathrm{~kg}$, height $1.52 \mathrm{~m}$ and BMI $18.0 \mathrm{~kg} / \mathrm{m}^{2}$ ) and gave birth to small and thin babies (full-term babies mean birth weight $2.65 \mathrm{~kg}$, ponderal index $24.5 \mathrm{~g} / \mathrm{cm}^{3}$ ). The body composition of Indian babies showed striking characteristics when compared with white Caucasian babies (mean birth weight $3.45 \mathrm{~kg}$, ponderal index $27.3 \mathrm{~g} / \mathrm{cm}^{3}$ ). Indian babies were small in all respects, but there was a pattern to their smallness. Birth weight, head circumference and height were smaller to a similar extent, soft tissues were differentially affected. Protein-rich soft tissues (skeletal muscle and abdominal viscera) were the most affected, while subcutaneous fat was the most preserved body component (Fig. 5). In other words, the small and thin growth-retarded Indian baby is thin in muscle and viscera but is relatively fat! We consider this as the 'Indian thrifty phenotype', which is remarkably similar to the 'thin and fat' adult Indian who is insulin resistant and is experiencing an epidemic of IRS in the last few decades. When we compared our newborn babies with those born in The Netherlands for whom both subscapular and triceps skinfolds were measured, it was obvious that in the Indian babies subscapular rather than triceps fat is deposited more predominantly, suggesting that the propensity of the Indians for central obesity is programmed in utero.

\section{Maternal determinants of fetal growth}

In our study (S Rao, CS Yajnik, A Kanade, CHD Fall, BM Margetts, AA Jackson, R Shier, S Joshi, S Rege and H Lubree, unpublished results) maternal intakes of energy and protein were not related to fetal growth, and maternal intake of fat was weakly related to birth weight. Frequency of consumption of dairy products, green leafy vegetables and fruits was associated with larger birth size. Maternal prepregnant body size was the most important determinant of fetal growth. Of maternal body components, head circumference (a surrogate of the mother's own early life growth and nutrition) was a significant determinant of all aspects of fetal growth, maternal height determined neonatal length, and maternal fat mass determined neonatal fat

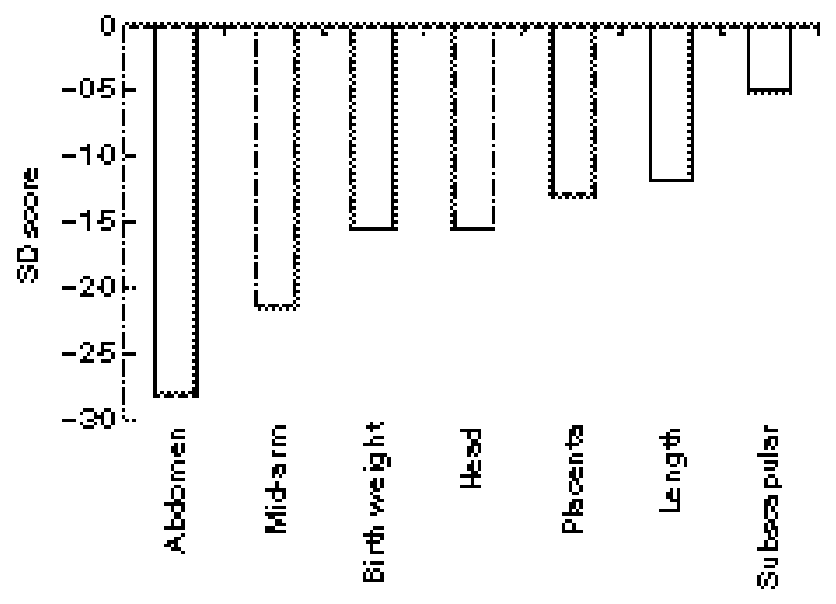

Fig. 5. Mean standard deviation scores for birth measurements in babies born in Pune (India) compared with babies born in Southampton (UK). The Southampton mean is represented as 0 . Abdomen, abdominal circumference; mid-arm, head, mid-arm and head circumferences respectively; placenta, placenta weight; subscapular, subscapular skinfold thickness. (Based on Fall et al. 1999.)

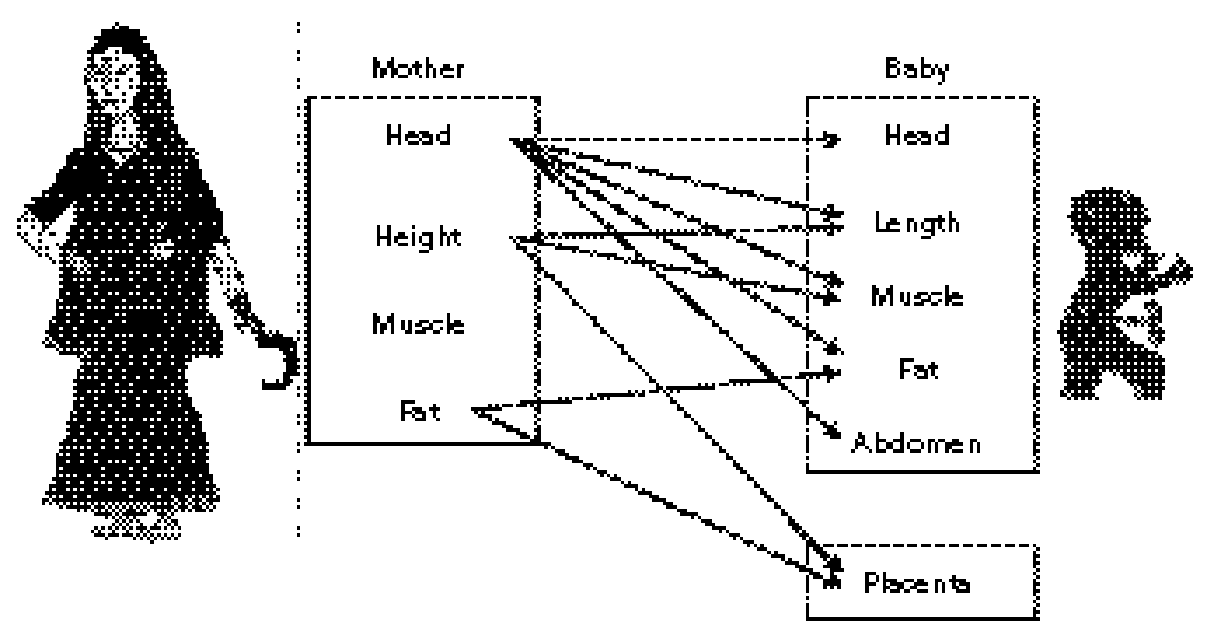

Fig. 6. Relationships between maternal anthropometric measurements before pregnancy and neonatal measurements at birth. Note that maternal head circumference (a surrogate for early-life growth and nutrition) is significantly related to all neonatal measurements except placental weight. Maternal height is related to neonatal height and muscle (mid-arm circumference), and maternal fat is related to neonatal fat (fat mass calculated from four skinfold thicknesses). Maternal muscle (mid-arm circumference) is not related to any of the neonatal anthropometric measurements. Placental weight is related to maternal height and fat. 
(Fig. 6). The fattest babies were born to mothers who were short and fat (poor growth in early life, energy excess in later years). Thus, maternal 'nutritional history' (as evident in different body measurements) was reflected in different body compartments of the fetus. We interprete our findings to indicate that a 'proportionate' improvement in fetal growth would require improved maternal nutrition throughout her life rather than nutritional supplementation after she becomes pregnant. Nutritional supplementation in late pregnancy (typical of all intervention programmes) might make babies more fat, without having a significant effect on brain (head) and skeletal (length) growth. Such a phenotype may improve neonatal survival, but could prove detrimental for long-term cardiovascular risk.

\section{Origins of insulin resistance syndrome: the biology of transition?}

Thus, in our studies we have been able to define a pattern of intrauterine growth in Indian babies which is organ and muscle depleted but fat preserving. The mechanisms linking these growth perturbations with IRS and increased cardiovascular risk are only beginning to be understood. The central issue seems to be the fundamental biological drive in a developing fetus to preserve the brain (head) growth. This growth is achieved by preferential diversion of blood flow to the head and by making other tissues insensitive to the action of insulin and related growth hormones. These adaptations allow diversion of nutrients from the developing peripheral tissues to the brain. At the cellular and molecular levels this adaptation is probably expressed as alterations in the structure of membranes as well as altered intracellular metabolic pathways. We speculate that the endocrine and metabolic adaptations which allow the best use of available nutrients for survival in utero programme the pathways of nutrient utilization in later life. In situations of positive energy balance this programming leads to excess fat deposition, especially in 'central' depots, which aggravates insulin resistance. There is recent exciting data to show that an adipocyte may influence insulin sensitivity and endothelial function not only by excess release of nonesterified fatty acids but also by release of a number of other molecules, including leptin and other proinflammatory cytokines (Mohamed Ali et al. 1997). An urban environment makes matters worse by providing a backdrop of a polluted and infective environment (Yudkin et al. 1999). Thus, babies born in countries undergoing a rapid transition would face malnutrition in their intrauterine life, and a state of relative overnutrition in later life which provides opportunities for 'catch up'. Babies which 'catch up' in body weight, fat and height are more insulin resistant as children. We need to investigate factors which determine which babies are able to catch up. The role of postnatal nutritional supplementation in the management of low-birth-weight babies needs to be carefully assessed, in view of the longterm effects of the insulin-resistant state on the development of diabetes and CHD (Haffner \& Miettinen, 1997). It may be more rewarding to avoid 'obesity' in those individuals who were small at birth. Given the strong association between socio-economic growth and increasing obesity there may be some inevitability to the occurrence of IRS in the developing populations. It is fascinating that the Indian saint Tukaram (1590 AD - 1630 AD) from Pune advised:

\section{ठेविले अनंते तैसेची रहावे चित्तीं असो द्यावे समाधान}

(live as God wished you to, be satisfied with what he has given you)'.

\section{Acknowledgements}

I am grateful to all my colleagues and collaborators who contributed to these studies, and The Wellcome Trust, London, UK, who funded the studies.

\section{References}

Barker DJP (1995) Fetal origins of coronary heart disease. British Medical Journal 311, 171-174.

Barker DJP (1998) Mothers, Babies and Health in Later Life. Edinburgh: Churchill Livingstone.

Barker DJP, Gluckman PD, Godfrey KM, Harding JE, Owens JA \& Robinson JS (1993a) Fetal nutrition and cardiovascular disease in adult life. Lancet 341, 938-941.

Barker DJP, Hales CN, Fall CHD, Osmond C, Phipps K \& Clark PMS (1993b) Type 2 (non-insulin-dependent) diabetes mellitus, hypertension and hyperlipidaemia (syndrome $\mathrm{X}$ ): relation to reduced fetal growth. Diabetologia 36, 62-67.

Barker M, Robinson S, Osmond C \& Barker DJP (1997) Birthweight and body fat distribution in adolescent girls. Archives of Disease in Childhood 77, 381-383.

Barker DJP, Winter PD, Osmond C, Margetts B \& Simmonds SJ (1989) Weight in infancy and death from ischaemic heart disease. Lancet ii, 577-580.

Bavdekar A, Yajnik CS, Fall CHD, Bapat S, Pandit A, Deshpande V, Bhave S, Kellingray S \& Joglekar C (1999) The insulin resistance syndrome (IRS) in eight-year-old Indian Children: small at birth, big at 8 years or both? Diabetes (In the Press).

Crowther NJ, Cameron N, Trusler J \& Gray IP (1998) Association between poor glucose tolerance and rapid postnatal weight gain in seven-year-old children. Diabetologia 41, 1163-1167.

Eriksson JG, Forsen T, Tuomilehto J, Winter PD, Osmond C \& Barker DJP (1999) Catch-up growth in childhood and death from coronary heart disease: longitudinal study. British Medical Journal 318, 427-431.

Fall CHD, Yajnik CS, Rao S \& Coyaji KJ (1999) The effects of maternal body composition before pregnancy on fetal growth; The Pune Maternal Nutrition Study. In Fetal Programming Influences on Development and Disease in Later life, pp. 231-245 [PMS O’Brien, T. Wheeler and DJP Barker, editors]. London: RCOG.

Gopalan C (1994) Low birth weight: significance and implications. In Nutrition in Children; Developing Country Concerns, pp. 1-33 [HPS Sachdev and P Chaudhury, editors]. New Delhi: Imprint.

Gupta R \& Gupta VP (1996) Meta-analysis of coronary heart disease prevalence in India. Indian Heart Journal 48, 241-245.

Haffner SM \& Miettinen H (1997) Insulin resistance implications for type II diabetes mellitus and coronary heart disease. American Journal of Medicine 103, 152-262.

Hales CN \& Barker DJP (1992) Type 2 (non-insulin-dependent) diabetes mellitus: the thrifty phenotype hypothesis. Diabetologia 35, 595-601. 
Hales CN, Barker DJP, Clark PMS, Cox LJ, Fall C \& Osmond C (1991) Fetal and infant growth and impaired glucose tolerance at age 64. British Medical Journal 303, 1019-1022.

Law CM, Barker DJP, Osmond C, Fall CHD \& Simmonds SJ (1992) Early growth and abdominal fatness in adult life. Journal of Epidemiology and Community Health 46, 184-186.

Malina RM, Katzmarzyk PT \& Beunen G (1996) Birth weight and its relationship to size attained and relative fat distribution at 7 to 12 years of age. Obesity Research 4, 385-390.

Matthews DR, Hosker JP, Rudenski AS, Naylor BA, Treacher DF \& Turner RC (1985) Homeostasis model assessment: insulin resistance and beta cell function from fasting glucose and insulin concentrations in man. Diabetologia 28, 412-419.

Mohamed Ali V, Goodrick S, Rawesh A, Miles JM, Katz D, Yudkin JS \& Coppack SW (1997) Human subcutaneous adipose tissue secretes interleukin- 6 but not tumour necrosis factor- $\alpha$ in vivo. Journal of Clinical Endocrinology and Metabolism 82, 4196-4200.

Neel JV (1962) Diabetes mellitus: A 'thrifty' genotype rendered detrimental by 'progress'? American Journal of Human Genetics 14, 353-361.

Ramachandran A, Snehalatha C, Latha E, Vijay V \& Viswanathan M (1997) Rising prevalence of NIDDM in an urban population in India. Diabetologia 40, 232-237.

Ravelli GP, Stein ZA \& Susser MW (1976) Obesity in young men after famine exposure in utero and early infancy. New England Journal of Medicine 295, 349-354.
Rose GA, Blackburn H, Gillum RF \& Prineas RJ (1982) Cardiovascular Survey Methods. Geneva: WHO.

Shelgikar KM \& Yajnik CS (1997) Cardiovascular risk of body mass index (BMI) in elderly rural Indians. A need to reassess obesity criteria? Diabetologia 40, A207.

Stein CE, Fall CHD, Kumaran K, Osmond C, Cox V \& Barker DJP (1996) Fetal growth and coronary heart disease in South India. Lancet 348, 1269-1273.

Strauss RS (1997) Effects of intrauterine environment on childhood growth. British Medical Bulletin 53, 81-95.

Valdez R, Athens MA, Thompson GH, Bradshaw BS \& Stern MP (1994) Birthweight and adult health outcomes in a biethnic population in the USA. Diabetologia 37, 624-631.

Whincup PF, Cook DG, Adshead F, Taylor SJC, Walker M, Papacosta O \& Alberti KGMM (1997) Childhood size is more strongly related than size at birth to glucose and insulin levels in 10-11 year-old children. Diabetologia 40, 319-326.

Whitaker RC \& Dietz WH (1998) Role of prenatal environment in the development of obesity. Journal of Pediatrics 132, 768-776.

Yajnik CS, Fall CHD, Vaidya U, Pandit AN, Bavdekar A, Bhat DS, Osmond C, Hales CN \& Barker DJP (1995) Fetal growth and glucose and insulin metabolism in four-year-old Indian children. Diabetic Medicine 12, 330-336.

Yudkin JS, Yajnik CS, Mohammed Ali V \& Bulmer K (1999) High levels of circulating proinflammatory cytokines and leptin in urban, but not rural, Asian Indians. Diabetes Care 22, 363-364. 